\title{
Sensitivity of Flux Footprint Modelling to Geographic Resolutions and Autocorrelation
}

\author{
Michael E. Hodgson, Alexandria McCombs and April Hiscox \\ USC, Columbia/SC, USA · hodgsonm@sc.edu
}

Short paper

\begin{abstract}
The standard practice of using moderate resolution satellite imagery for carbon flux studies at Ameriflux sites is called into question. In this study, a flux footprint model was implemented for modelling the carbon source areas for an Ameriflux site in Oklahoma using one year of carbon flux and meteorological measurements. A sensitivity analysis was conducted using cell sizes from $1 \mathrm{~m}$ to $30 \mathrm{~m}$ for the study site. The results indicate that over $95 \%$ of the source locations are within $93 \mathrm{~m}$ of the carbon flux receptor. Knowing the spatial accuracy is typically no better than $1 / 2$ cell size, suggests that cell sizes of less than $45 \mathrm{~m}$ introduces far greater uncertainty than is appropriate.
\end{abstract}

\section{Introduction}

Estimating the source of airborne constituents (e.g. gas, dust) is a continual problem in geographic health problems, terrorism, and even climate change research. A high methane concentration might be indicative of accidental burning of materials, while chlorine might suggest releases from anthropogenic sources. But where did the air mass come from? The observed air mass may be a composite of multiple sources over a relatively short period of time.

Flux footprint modelling, an approach developed in boundary-layer meteorology, is a method to identify the probable source areas and the relative contribution of a single point flux measurement (SCHMID 2002). A number of footprint models have been developed, each with varying degrees of complexity and specific limitations on the atmospheric conditions under which they are valid. These models range from a relatively simple one dimensional solution (e.g. HORST \& WEIL, 1992), two-dimensional solutions with cross-wind components (e.g. KAHARABATA et al. 1997), or three dimensional Langragian or Large-Eddy Simulations Models (e.g. PRABHA et al. 2008). At a minimum, the flux models require wind measurements (e.g. three component wind measurements as $u, v, w$ ) and either assumptions or observations of the air temperature, humidity, pressure, and canopy height. The geographic distribution of land cover and topography, as well as air temperature and precipitation are also important variables in the air mass trajectory and potential source contribution of carbon dioxide (WYLIE et al. 2007). Many of these models assume a homogeneous land cover so that the complexity of changing surface roughness is not accounted for. Recent work has attempted to account for the changes in land surface conditions in the trajectory path of an air mass (e.g. HSIEH \& KATUL 2009). 
The footprint model used in this study was developed by Hsieh et al. (2000), which is a 1dimensional analytical footprint model. The model does not account for crosswind dispersion of gases in the trajectory path of an air mass and does not account for changing surfaces conditions such as land cover, surface roughness, or the amount of latent and sensible heat at the surface. The footprint function is calculated using the following:

$$
f\left(x, z_{m}\right)=\frac{1}{k^{2}} D z_{u}^{P}|L|^{1-P} \exp \left(\frac{-1}{k^{2} x} D z_{u}^{P}|L|^{1-P}\right)
$$

where $x$ is the distance from the site, $z_{m}$ is the measurement height, and $z_{u}$ is the length scale that is computed using the measurement height and the roughness length with the equation found in Hsieh et al. (2000). The parameters for $D$ and $P$ are determined based on the atmospheric stability. The function is the probability of a source area from location $x$ (Figure 1). The derived functional value can be positive, a source of $\mathrm{CO}_{2}$, or negative, a sink for $\mathrm{CO}_{2}$. Relating source area to land cover and management practices is a spatial and temporal resolution challenge. What is an appropriate spatial resolution? What is a minimal spatial resolution? The distance of the source to the receptor varies with meteorological conditions and receptor height. For instance, SOEGAARD et al (2000) found that $80 \%$ of the source area was within $200 \mathrm{~m}$ of a $3 \mathrm{~m}$ height receptor in Greenland.

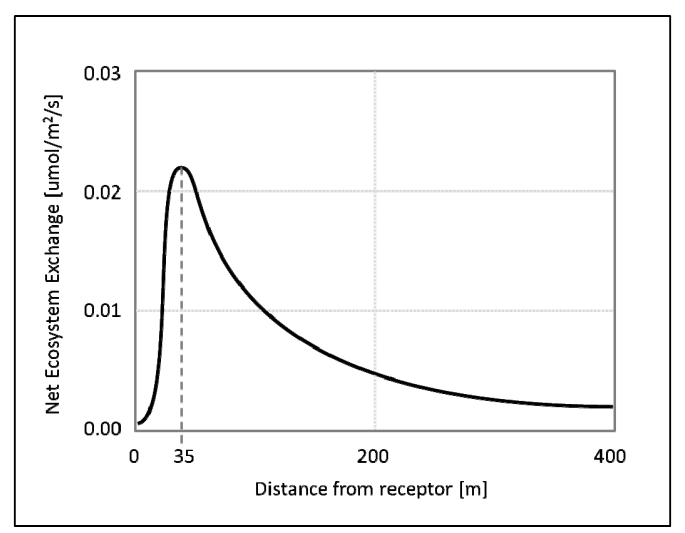

Fig. 1:

1-Dimensional footprint modelled from 30-minute observation on 26 January 2004

\section{Methodology}

In this research we are modelling the cumulative net ecosystem exchange for a one year time period. Thus, we use the entire functional probability (maxima and other locations along the curve). A probability surface is derived for each wind measurement (e.g. one 30minute average). The footprint function was calculated for $x$ and then the source contribution from $x$ to $x+1$ is calculated using a trapezoidal numerical analysis approximation technique to integrate the area under the functional curve. Some researchers use only the location $\mathrm{x}$ of the functional maxima to indicate the source. A cumulative contribution probability is derived for each location (i.e. cell) within the study area from each 1-dimensional function and for each observation over the time period (1 January, 2004 through December $31,2004)$. For this study site in Oklahoma, and for typical winds, the functional maxima are typically in the 20 to $50 \mathrm{~m}$ distance from the receptor location. 
An understanding of the geographic scale of analysis (e.g. spatial resolution or temporal resolution) are known to have effects on geographic models in other applications (e.g. CHOw \& Hodgson 2009, KAR \& HodGSON 2012). What is the sensitivity of the flux footprint model to the geographic scale of analysis? We also suggest the uncertainty in source area types can also be related to the spatial autocorrelation in land cover. If the goal is to identify the source area types then the precision in geographic source locations may not be necessary if the spatial autocorrelation in land cover is high. Thus, consideration of sensitivity of modelled results is a function of not only geographic scale but of the spatial autocorrelation in land cover types (or autocorrelation in other variables for example).

In this study we use both actual meteorological station sites (e.g. ARM Southern Great Plains AmeriFlux station) and simulated data (to control for spatial autocorrelation) to examine the functional relationship between geographic scale, spatial autocorrelation, and modelled flux output. We analysed the model runs using geographic resolutions from 1 to 30 meters (the range of appropriate for LandSat satellite observations). We then constructed functional relationships between spatial resolution, spatial autocorrelation, and variations in modelled output.

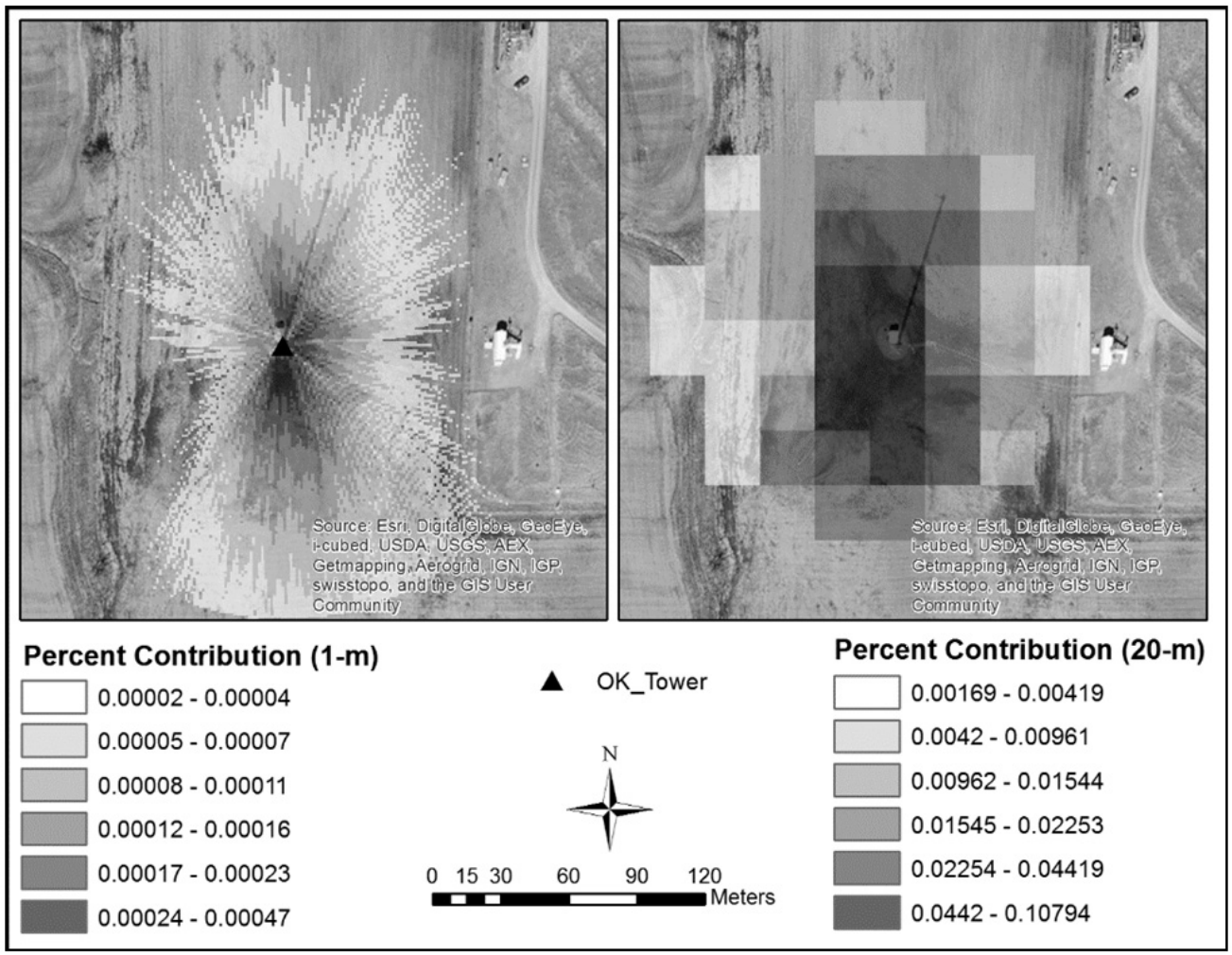

Fig. 2: Modelled footprints for composite 30-min observations during 2004 


\section{Results}

Almost 95\% of the footprint modelled source area for the year 2004 is contained within $93 \mathrm{~m}$ of the receptor location (Figure 2). Fifty percent of the source area is within $45 \mathrm{~m}$ of the receptor. Thus, the land use/cover, management practice, and soil-vegetative conditions within this $93 \mathrm{~m}$ buffered area are the dominant control of carbon flux observed at the receptor location. Using larger cell sizes (e.g. $100 \mathrm{~m}, 500 \mathrm{~m}$, etc.) clearly demonstrates the generalization within this sensitive area. What is immediately apparent is the sensitivity of the modelled area to the larger cell sizes, such as Aqua/Terra MODIS (250 m to $1000 \mathrm{~m}$ ) imagery. The use of moderate resolution imagery, such as the freely available Landsat $(15 \mathrm{~m}$ or $30 \mathrm{~m})$ imagery, exacerbates the problem of representing carbon source areas for such receptor-based studies.

\section{References}

Chow, T. E. \& Hodgson, M. E. (2009), Effects of Lidar Post-Spacing and DEM Resolution to Mean Slope Estimation. International Journal of Geographical Information Science, 23, 1277-1295.

Horst, T. W. \& WeIL, J. C. (1992), Footprint estimation for scalar flux measurements in the atmospheric surface layer. Boundary-Layer Meteorology, 59, 279-296.

HsieH, C.-I., KATUl, G. \& CHI, T.-W. (2000), An approximate analytical model for footprint estimation of scalar fluxes in thermally stratified atmospheric flows. Advances in Water Resources, 23, 765-772.

HSIEH, C.-I. \& KATUL, G. (2009), The Lagrangian stochastic model for estimating footprint and water vapor fluxes over inhomogeneous surfaces. International Journal of Biometeorology, 53, 87-100.

Kaharabata, S. K., Schuept, P. H., Ogunjemiyo, S., Shen, S., Leclarc, M. Y., DESJARDINS, R. L. \& MAPHERSON, J. I. (1997), Footprint considerations in BOREAS. Journal of Geophysical Research, 102, D24, 29113-29124.

KAR, B. \& Hodgson, M. E. (2012), Observational Scale and Modeled Potential Residential Loss from a Storm Surge. GIScience and Remote Sensing, 49, 202-227.

PrabHa, T., LeClerC, M. Y. \& BALDOCCHI, D. (2008), Comparison of in-canopy flux footprints between Large-Eddy Simulation and the Lagrangian simulation. Journal of Applied Meteorology and Climatology, 47, 2115-2128.

Soegaard, H., Nordstroem, C., Friborg, T., Hansen, B. U., Christensen, T. R. \& Bay, C. (2000), Trace gas exchange in a high-arctic valley 3 . Integrating and scaling $\mathrm{CO}_{2}$ fluxes from canopy to landscape using flux data, footprint modeling, and remote sensing. Global Biogeochemical Cycles, 14, 725-744.

SCHMID, H. P. (2002), Footprint modeling for vegetation atmosphere exchange studies: a review and perspective. Agricultural and Forest Meteorology, 113, 159-183.

Wylie, B. K., Fosnight, E. A., Gilmanov, T. G., Frank, A. B., Morgan, J. A., HaferKAMP, M. R., \& MEYERS, T. P. (2007), Adaptive data-driven models for estimateing carbon fluxes in the Northern Great Plains. Remote Sensing of Environment, 106 (4), 399-413. DOI:10.1016/j.rse.2006.09.017. 